\title{
Passive Nitrogen Oxides Removal from a Diesel-engine Exhaust Gas Using a Biomass-carbon Catalyst
}

\author{
Melvina Tan ${ }^{\mathrm{a}}$, Ibrahim Yakub,a and Taufiq-Yap Yun Hin ${ }^{\mathrm{b}, \mathrm{c}}$ \\ ${ }^{a}$ Department of Chemical Engineering and Energy Sustainability, Faculty of Engineering, \\ Universiti Malaysia Sarawak, 94300 Kota Samarahan, Sarawak, Malaysia \\ ${ }^{b}$ Catalysis Science and Technology Research Centre (PutraCAT), Faculty of Science, \\ Universiti Putra Malaysia, 43400 UPM Serdang, Selangor, Malaysia \\ ${ }^{c}$ Chancellory Office, Universiti Malaysia Sabah, 88400 Kota Kinabalu, Malaysia
}

\begin{abstract}
Nitrogen oxides $\left(\mathrm{NO}_{x}\right)$ removal from a diesel-engine exhaust gas requires the utilization of ammonia/urea as a reducing agent (SCR) which arose environmental concerns over the use of this chemical. Therefore, this study explored the potential of using a sustainable $N O_{x}$ removal system by replacing ammonia with intrinsic reductants present in the exhaust gas, such as hydrocarbons and carbon monoxide, and by application of cost-effective carbon-supported transitional metals catalyst. Copper-cerium catalyst supported over palm kernel shell activated carbon (Cu-Ce/PKS) was synthesized via deposition-precipitation method. The characterization shows that the catalyst has a considerably high surface area (though lower than the support). The high $\mathrm{NO}_{x}$ removal by $\mathrm{Cu}-\mathrm{Ce} / \mathrm{PKS}$ in a passive catalytic reaction is attributable to the surface area provided by the carbon support, the low copper reducibility which leads to the low optimum operating temperature, and the synergistic effect between $\mathrm{Cu}$ and $\mathrm{Ce}$ which resulted in the wide temperature window at low-temperature range. It is concluded that $\mathrm{Cu}$-Ce supported over palm kernel shell activated carbon can be further developed to reduce $\mathrm{NO}_{x}$ in a passive catalytic removal for a sustainable and cost-effective SCR system.
\end{abstract}

Keywords: $N O_{x}$ removal, Passive catalytic reduction, Carbon-supported catalyst, Depositionprecipitation method, Synergistic effect

\section{Introduction}

Nitrogen oxides $\left(\mathrm{NO}_{\mathrm{x}}\right)$ emitted from combustion/incineration processes typically consist of $95 \%$ nitric oxide $(\mathrm{NO})$ and $5 \%$ nitrogen dioxide $\left(\mathrm{NO}_{2}\right)$, where $\mathrm{NO}$ is considered as the most difficult compound to remove from ambient air for it is nearly insoluble in water [1] [2]. Ammonia-selective catalytic reduction (SCR) is a commonly used technique to remove this toxic gas from an exhaust/flue gas emission. However, a phenomenon called ammonia slip, where the unreacted ammonia is also emitted in the exhaust gas prompted studies on the ammonia replacement as a reducing agent. Among the attractive methods to reduce $\mathrm{NO}_{\mathrm{x}}$ emissions from the combustion flue gas is selective catalytic reduction with hydrocarbons (HC-SCR) and/or carbon monoxide (CO-SCR). It is known that both HC and $\mathrm{CO}$ are present in a diesel engine exhaust gas due to the incomplete combustion of the fuel. By utilizing the intrinsic carbon monoxide and unburned hydrocarbons to replace ammonia as a reductant in SCR, the cost of $\mathrm{NO}_{\mathrm{x}}$ removal can be reduced because of the elimination of ammonia/urea injection

\footnotetext{
* Corresponding author. Tel.: +082-584584; Fax: +082-583410

E-mail address: yibrahim@unimas.my

Manuscript History:

Received 16 April, 2020, Revised 28 April, 2020, Accepted 29 April, 2020, Published 30 April, 2020
}

e-ISSN: 2289-7771 
system [3]. There are two modes of SCR: the usage of the intrinsic $\mathrm{HC}$ and $\mathrm{CO}$ in the exhaust gas, known as the passive mode; and by injecting additional $\mathrm{HC}$ and/or $\mathrm{CO}$, which is called the active mode - the former being the interest of this research study [4].

Copper and cerium are among the most commonly studied transitional metal catalysts in SCR. Both of these metals have lower costs as compared to precious metals and typically have a higher resistance to sulphur compounds, water poisoning, and carbon dioxide [5]. Copper is known to exhibit high activity which is enhanced by the presence of oxygen, while cerium has been widely used as an active species or an additive because of its unique redox and acid-base properties [6] [7]. It was reported that cerium oxide enhanced the oxidation of $\mathrm{NO}$ to $\mathrm{NO}_{2}$, leading to an enhanced SCR activity [7] [8]. With these advantages, $\mathrm{Cu}$ and $\mathrm{Ce}$ could be considered as excellent catalysts for a passive SCR.

Activated carbon (AC) is a black and amorphous solid containing a major portion of fixed carbon content, volatile matters and ash. Due to its large internal pore structures and pore volume, AC has a high adsorbing capacity for most compounds. This highly developed porous structure has resulted from the processing of carbonaceous raw materials under high-temperature reactions [9]. Besides acting as an adsorbent, activated carbon can also be applied as a catalyst and catalyst support to metal oxide catalysts. This is because, in addition to porosity, surface chemistry of the carbon is also contributing to the catalyst reactivity [10].

Palm kernel shell (PKS) has been one of the most promising precursors for the production of high-grade activated carbon as it has high density, high carbon content and low ash properties [11]. In Malaysia, there is a high potential for the application and production of activated carbon using PKS. The production of oil palm fresh fruit bunch (FFB) saw an increment from 48 million to 70 million from 2000 to 2012, and an additional of 315,306 ha of oil palm (6\% increase from 2012) were planted since then [12] [13]. This showed positive growth in the future years for the plantation, and PKS will also increase as each tonne of FFB produces approximately $55 \mathrm{~kg}$ of PKS [13]. Because most of the portions were under-utilized, PKS can be used as a sustainable raw material for the activated carbon production. Biomass waste utilization is relatively economical because it is sourced from agricultural wastes which are readily available. Therefore, activated carbon from biomass waste has a lower capital cost and is favoured in the application of removing $\mathrm{NO}_{\mathrm{x}}$ gases [14]. Considering the state-of-the-art of the passive SCR and the advantages of using PKS, the aim of this study is to investigate the performance of PKS-supported Cu-Ce catalyst in a passive catalytic removal of $\mathrm{NO}_{\mathrm{x}}$ gases.

\section{Materials and method}

\subsection{Catalyst synthesis}

Activated carbon derived from palm kernel shell was obtained from a local supplier and dried in a laboratory oven overnight at $110{ }^{\circ} \mathrm{C}$. The catalysts were prepared by using the depositionprecipitation method with urea as the precipitating agent. $50 \mathrm{~g}$ of activated carbon was weighed, and metal salts (copper and cerium) were dissolved using deionized water in a separate beaker. The $\mathrm{Cu}: \mathrm{Ce}$ ratio was $1: 1$ for the bimetallic $\mathrm{Cu}-\mathrm{Ce} / \mathrm{PKS}$ with $10 \mathrm{wt} \%$ total loading, and the loading was kept constant for the monometallic catalysts $\mathrm{Cu} / \mathrm{PKS}$ and $\mathrm{Ce} / \mathrm{PKS}$. The metal solutions were mixed with the activated carbon and stirred well for 15 mins before $15 \mathrm{~mL}$ of $1 \mathrm{M}$ urea solution was poured into the mixture and stirred at $90{ }^{\circ} \mathrm{C}$ for $6 \mathrm{~h}$. Subsequently, the slurry was filtered to remove the excess solution, washed until it was clear, and dried at $110{ }^{\circ} \mathrm{C}$ in an oven overnight, followed by calcination at $250{ }^{\circ} \mathrm{C}$ for $4 \mathrm{~h}$ in a furnace. 


\subsection{Passive $\mathrm{NO}_{\mathrm{x}}$ catalytic removal}

The catalytic activity was studied at a temperature between 140 and $300{ }^{\circ} \mathrm{C}$ with $40{ }^{\circ} \mathrm{C}$ interval. An air-cooled 4-stroke single-cylinder diesel engine of at least $3000 \mathrm{rpm}$ was used in this experiment. The exhaust from this engine was connected to a filter to remove soot and liquid effluent before entering a catalytic bed of $20 \mathrm{~mm}$ inner diameter. Testo 350 XL Flue Gas Analyser (Germany) was used to measure the concentration of $\mathrm{NO}_{\mathrm{x}}$ before and after the reactor. $10 \mathrm{~g}$ of the catalyst was placed inside the reactor and heated to the desired temperature. Then, the valve connecting the exhaust and the reactor was turned on. The flow rate of flue gas was fixed to $1 \mathrm{~L} / \mathrm{min}$ giving $3000 \mathrm{~h}^{-1} \mathrm{GHSV}$. No external source of hydrocarbon or carbon monoxide was injected to resemble the passive mode of this system. No repetition was made to avoid the excessive release of toxic $\mathrm{NO}_{\mathrm{x}}$. The experiment was carried out until equilibrium $\mathrm{NO}_{\mathrm{x}}$ concentration was obtained and was performed for different catalysts; $\mathrm{PKS}, \mathrm{Cu} / \mathrm{PKS}, \mathrm{Ce} / \mathrm{PKS}$ and $\mathrm{Cu}-\mathrm{Ce} / \mathrm{PKS}$ respectively.

\subsection{Catalyst characterization}

The carbon support (PKS), the monometallic catalysts $(\mathrm{Cu} / \mathrm{PKS}$ and $\mathrm{Ce} / \mathrm{PKS})$ and the bimetallic catalyst $(\mathrm{Cu}-\mathrm{Ce} / \mathrm{PKS})$ were characterized to determine the contribution of each of the elements (carbon support, $\mathrm{Cu}$ and $\mathrm{Ce}$ ) on the performance of $\mathrm{Cu}-\mathrm{Ce} / \mathrm{PKS}$. The Brunauer-Emmet-Teller (BET) surface area was determined via a nitrogen adsorption-desorption experiment, the presence of the surface functional groups was observed using Fourier-Transform Infra-Red (FTIR), the distribution of copper and cerium particles on the catalyst was perceived from an energy dispersive X-ray fluorescence (XRF), and the reducibility of the catalysts was determined by a temperatureprogrammed reduction (TPR).

0.2 to $0.3 \mathrm{~g}$ of the sample was placed into a quartz U-tube and contacted with nitrogen gas at a relative pressure $\left(\mathrm{P} / \mathrm{P}_{0}\right)$ of up to 1.00 . Nitrogen adsorption-desorption was measured using Autosorb iQ Automated Gas Sorption (USA) at liquid nitrogen temperature $\left(-196^{\circ} \mathrm{C}\right)$. BET method was used to calculate the specific surface area and pore volume. $0.1 \mathrm{~g}$ of the sample was mixed with $1.0 \mathrm{~g}$ of $\mathrm{KBr}$ and pressed to become a solid disc. The disc was then placed in an oven at $105{ }^{\circ} \mathrm{C}$ for $4 \mathrm{~h}$ to prevent any interference with water vapour molecules. The analysis was performed by using a Thermo Nicolet 380 (USA) with the wavelength ranging from 400 to $4000 \mathrm{~cm}^{-1}$. The change in the FTIR spectra was observed after deposition with catalysts showing the effects on the surface functional groups.

The sample (about $0.1 \mathrm{~g}$ ) was crushed into powder form and placed on a stub in an EDX720/800HS Energy Dispersive X-ray Fluorescence (Japan). It was exposed to X-ray radiation, and a set of energy released corresponds to a specific type of inorganic matter present in the sample. The standard deviation for the composition represents the distribution of the metal over the material surfaces. The most efficient reduction temperature for the impregnated catalyst was studied by using a hydrogen temperature-programmed reduction (TPR). This analysis was performed using a Thermo Finnigan TPDRO 1100 (USA), where approximately $20 \mathrm{mg}$ of the sample was reduced under a $5 \%$ hydrogen gas at $10{ }^{\circ} \mathrm{C} / \mathrm{min}$ until $950{ }^{\circ} \mathrm{C}$. The area under the TPR curve represents the amount of hydrogen being consumed by the sample reflecting the reduction activity at a particular temperature.

\section{Results and discussion}

\subsection{Performance of $\mathrm{Cu}-\mathrm{Ce}$ bimetallic catalyst in a passive $\mathrm{NO}_{\mathrm{x}}$ removal}

The activity of $\mathrm{Cu}-\mathrm{Ce} / \mathrm{PKS}$ in removing $\mathrm{NO}_{\mathrm{x}}$ gases was evaluated in a passive SCR mode, and the results are shown in Figure 1. The catalyst exhibited increased removal percentage at low temperature but not at high temperature as compared to the raw PKS and the monometallic catalysts. 
However, on overall, $\mathrm{Cu}-\mathrm{Ce} / \mathrm{PKS}$ gave the highest $\mathrm{NO}_{\mathrm{x}}$ removal percentage with $66 \%$ removal at 140 ${ }^{\circ} \mathrm{C}$.

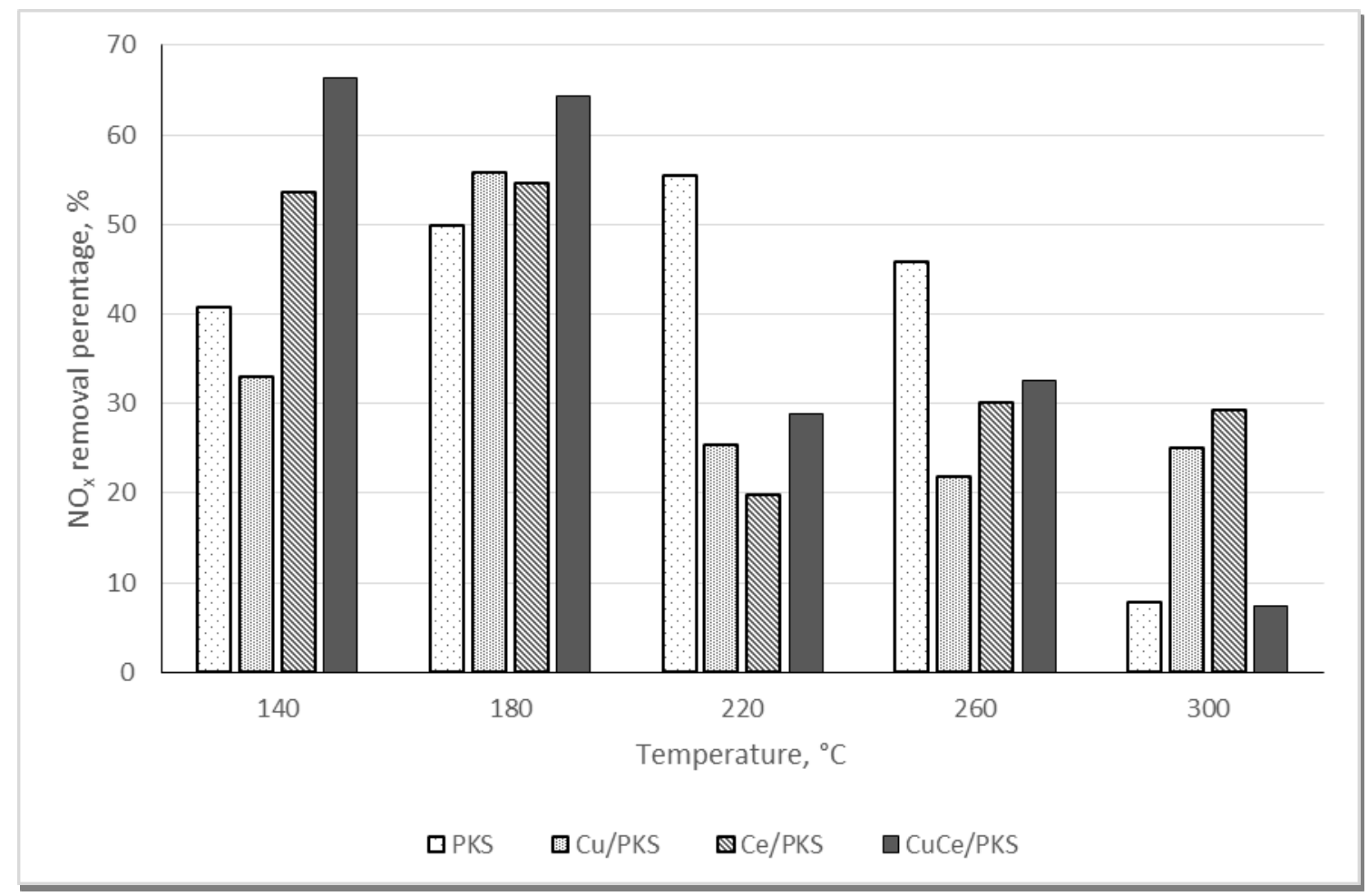

Figure $1 . \mathrm{NO}_{\mathrm{x}}$ removal percentage at different temperatures.

This showed that $\mathrm{Cu}-\mathrm{Ce} / \mathrm{PKS}$ exhibited a synergistic effect at low temperature. The increase in catalytic activity because of the interactions between $\mathrm{Cu}$ and $\mathrm{Ce}$ was also reported by other studies [15] [16]. The composition and distribution of transitional metal catalysts in all samples are obtained using XRF, which is presented in Table 1. It shows that $\mathrm{Cu}-\mathrm{Ce} / \mathrm{PKS}$ had an improved metal distribution in comparison to the monometallic catalysts. Ce/PKS had a poor metal distribution on the carbon surface that could be due to its aggregation affinity, but the loading was better than $\mathrm{Cu} / \mathrm{PKS}$. However, the interaction between $\mathrm{Cu}$ and $\mathrm{Ce}$ in $\mathrm{Cu}-\mathrm{Ce} / \mathrm{PKS}$ caused higher loading of $\mathrm{Cu}$ and less aggregation by $\mathrm{Ce}$, which resulted in a homogeneous catalysts distribution. Pang et al. (2014) [15] suggested that $\mathrm{Ce}$ was responsible for improving the metallic catalyst distribution and for reducing the aggregation of bimetallic $\mathrm{Cu}-\mathrm{Ce}$ when impregnated on ZMS-5.

Table 1. Metals composition and distribution from XRF analysis.

\begin{tabular}{|c|c|c|c|c|c|c|c|}
\hline \multirow{2}{*}{ Catalyst } & \multicolumn{5}{|c|}{ Weight of metal oxide (\%) } & \multirow{2}{*}{$\begin{array}{c}\text { Standard } \\
\text { deviation }\end{array}$} \\
\cline { 2 - 7 } & $\mathrm{CuO}$ & $\mathrm{CeO}_{2}$ & $\mathrm{SiO}_{2}$ & $\mathrm{~K}_{2} \mathrm{O}$ & $\mathrm{CaO}$ & $\mathrm{SO}_{3}$ & \\
\hline $\mathrm{Cu} / \mathrm{PKS}$ & 82.6 & 0 & 14.58 & 1.14 & 0.74 & 0.94 & 0.065 \\
\hline $\mathrm{Ce} / \mathrm{PKS}$ & 0 & 91.2 & 6.83 & 0.62 & 0.37 & 0.89 & 0.150 \\
\hline $\mathrm{Cu}-\mathrm{Ce} / \mathrm{PKS}$ & 64.95 & 14.57 & 17.33 & 1.17 & 0.97 & 1.02 & $\begin{array}{l}0.058^{\mathrm{a}} \\
0.057^{\mathrm{b}}\end{array}$ \\
\hline
\end{tabular}

*a denotes standard deviation of copper; $b$ denotes standard deviation of cerium 
On the contrary, very low $\mathrm{NO}_{\mathrm{x}}$ reduction was obtained when $\mathrm{Cu}-\mathrm{Ce} / \mathrm{PKS}$ was applied at higher temperature, which is similar to PKS. This suggests that the performance of the bimetallic catalyst depends highly on the carbon support, where the reduced ability of the support to adsorb $\mathrm{NO}_{\mathrm{x}}$ at high temperature affects the reduction process by the catalysts. This is discussed further in the following section.

\subsection{Role of the palm kernel shell activated carbon as a catalyst support}

The passive catalytic removal of $\mathrm{NO}_{\mathrm{x}}$ was also performed using raw PKS to study the role of the catalyst support. It was observed (from Figure 1) that the reduction increased with increasing temperature up to $220{ }^{\circ} \mathrm{C}$. Beyond this temperature, PKS showed reduced in performance, where it severely dropped at the highest temperature by almost $40 \%$. Some research groups suggested that the decrease in the performance of carbon-based catalyst at high temperature was due to the reduced amount of $\mathrm{NO}_{2}$ being adsorbed by the carbon support [17] [18].

The $\mathrm{NO}_{\mathrm{x}}$ adsorption was known to be correlated with the BET surface area [19] [20] [21]. Table 2 shows that PKS had the largest surface area and pore volume followed by $\mathrm{Cu} / \mathrm{PKS}$ and $\mathrm{Cu}-\mathrm{Ce} / \mathrm{PKS}$ that had similar value, and the least was $\mathrm{Ce} / \mathrm{PKS}$. From Figure 1, the $\mathrm{NO}_{\mathrm{x}}$ removal performance at PKS's optimal temperature $\left(220^{\circ} \mathrm{C}\right)$ showed this identical trend which validated the fact that BET surface area was an important property to a good SCR catalyst. However, at other temperatures, this was not the case, and the catalytic activity of a catalyst depended on other factors such as surface functional groups [22] [23] [24].

Table 2. Surface area and pore volume for PKS and its derivative catalysts.

\begin{tabular}{|c|c|c|}
\hline Sample & $\begin{array}{c}\text { BET Surface area } \\
\left(\mathrm{m}^{2} / \mathrm{g}\right)\end{array}$ & $\begin{array}{c}\text { Pore volume } \\
\left(\mathrm{cm}^{3} / \mathrm{g}\right)\end{array}$ \\
\hline $\mathrm{PKS}$ & 1126 & 0.5260 \\
\hline $\mathrm{Cu} / \mathrm{PKS}$ & 762 & 0.3716 \\
\hline $\mathrm{Ce} / \mathrm{PKS}$ & 563 & 0.2550 \\
\hline $\mathrm{Cu}-\mathrm{Ce} / \mathrm{PKS}$ & 707 & 0.3281 \\
\hline
\end{tabular}

Figure 2 compares the FTIR peaks of all samples which resemble the change in the surface functional groups upon different metals impregnation. It can be seen between peaks 3600 and $4000 \mathrm{~cm}^{-1}$ that PKS contained unsaturated surface functional group $(\mathrm{C}=\mathrm{C}-\mathrm{H})$ which was the characteristic band of activated carbon. This group was diminished after the synthesis of the catalyst as the peaks were not observable in all of the catalyst samples showing the utilization of this bond as catalytic anchoring sites. In addition, other oxygenated groups $\left(1600-1800 \mathrm{~cm}^{-1}\right)$ that can be found in PKS were shifted in the catalyst samples showing the used-up of these sites as the metallic catalyst bonding to the surface [25]. 


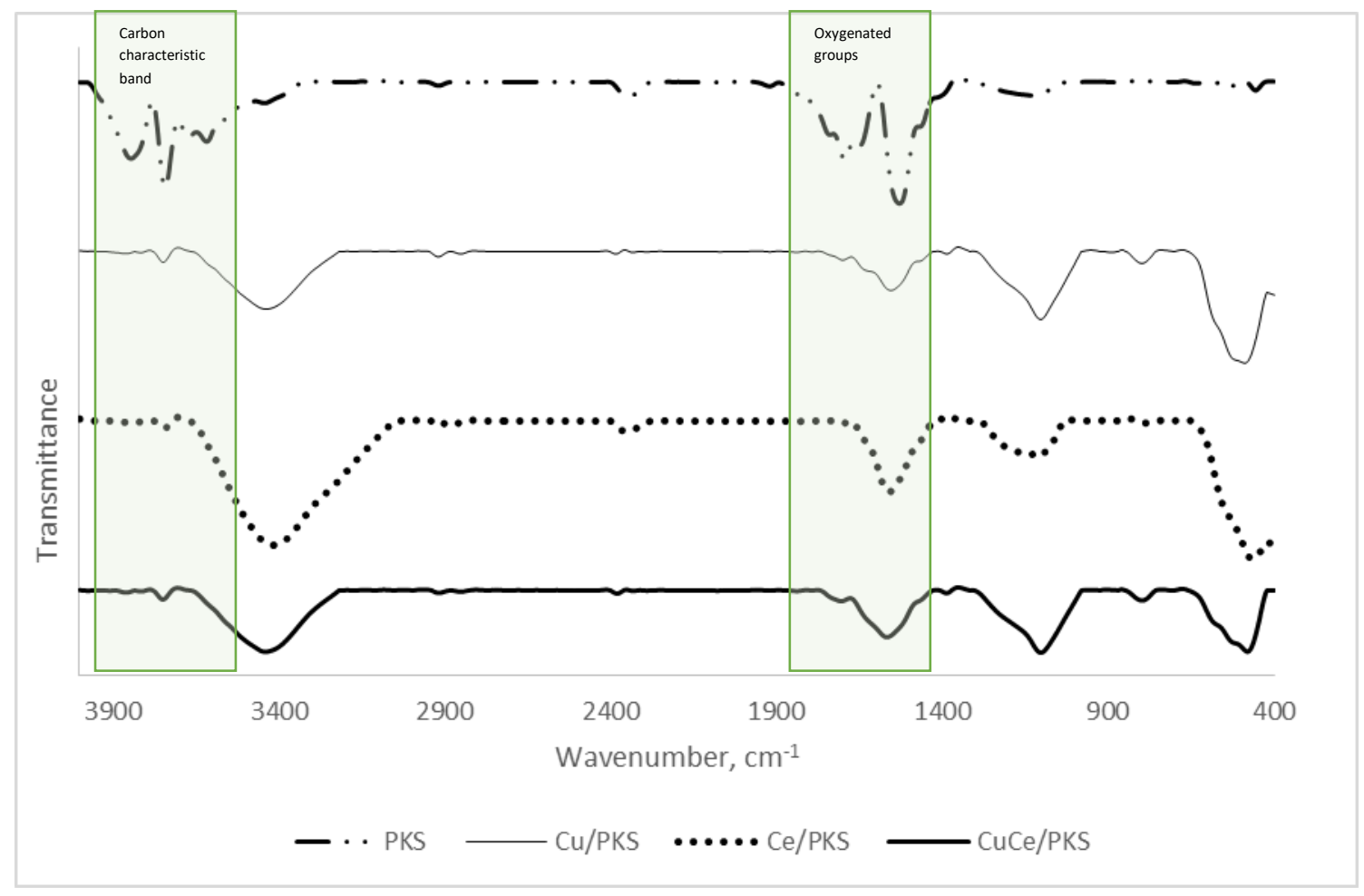

Figure 2. FTIR spectra for PKS, $\mathrm{Cu} / \mathrm{PKS}, \mathrm{Ce} / \mathrm{PKS}$ and $\mathrm{Cu}-\mathrm{Ce} / \mathrm{PKS}$.

\subsection{Effects of copper}

As copper was deposited on PKS, the removal efficiencies dropped at most of the temperatures, especially above $180{ }^{\circ} \mathrm{C}$ (refer figure 1). Chen et al. (2015) [19] used an ordered mesoporous carbon as catalyst support and found that the overall catalytic activity increased with increasing temperature of up to $250{ }^{\circ} \mathrm{C}$ before severely dropped when copper was embedded in a cerium-based catalyst. In a separate study and under hydrocarbon environment, Iwamoto et al. (1991) [26] explained that copper is not deactivated, but the oxidation of hydrocarbon at high temperature caused the decrease in the $\mathrm{NO}_{\mathrm{x}}$ conversion.

However, the optimum removal temperature was shifted to the lower range that was from 220 ${ }^{\circ} \mathrm{C}$ for PKS to $180{ }^{\circ} \mathrm{C}$ for $\mathrm{Cu} / \mathrm{PKS}$. Most of the optimum temperatures for copper-supported catalysts reported in the literature were above $200{ }^{\circ} \mathrm{C}$, but $\mathrm{Zhu}$ et al. (2015) [27] found that Fe-Cu/ZSM-5 catalyst possessed optimum temperature starting at $180{ }^{\circ} \mathrm{C}$. The lowered optimum temperature is especially favoured in the application of vehicles and industrial de- $\mathrm{NO}_{\mathrm{x}}$ system for the lower cost and energy recovery potentials [28].

The catalytic activity of copper at low temperature can be attributed to its reducibility property at such condition. The reduction of $\mathrm{CuO}$ may occur in one to two steps. The two-step common sequential reduction for $\mathrm{CuO}$ and $\mathrm{Cu}_{2} \mathrm{O}$ is represented by equations (1) and (2) whereas equation (3) shows the direct reduction pathway of $\mathrm{CuO}$ [29].

$$
\begin{aligned}
& 2 \mathrm{CuO}+\mathrm{H}_{2} \rightarrow \mathrm{Cu}_{2} \mathrm{O}+\mathrm{H}_{2} \mathrm{O} \\
& \mathrm{Cu}_{2} \mathrm{O}+\mathrm{H}_{2} \rightarrow 2 \mathrm{Cu}+\mathrm{H}_{2} \mathrm{O} \\
& \mathrm{CuO}+\mathrm{H}_{2} \rightarrow \mathrm{Cu}+\mathrm{H}_{2} \mathrm{O}
\end{aligned}
$$


Generally, $\mathrm{H}_{2}$-consumption profile for $\mathrm{Cu}$ catalyst is represented by three peaks at around 230 , 430 and $550{ }^{\circ} \mathrm{C}$. The first and the third peaks could be assigned to the reduction of isolated $\mathrm{Cu}^{2+}$ to $\mathrm{Cu}^{+}$and furthered to $\mathrm{Cu}^{0}$, respectively. The other peak was due to the direct reduction of $\mathrm{CuO}$ to $\mathrm{Cu}^{0}$ [30]. However, Figure 3(b) shows only one peak appeared at $311^{\circ} \mathrm{C}$ for $\mathrm{Cu} / \mathrm{PKS}$ on top of the peaks occurring for PKS in Figure 3(a). The broad peak at the highest temperature was contributed by the hydrogenation by carbonaceous species [30]. Therefore, it can be inferred that the partial reduction of $\mathrm{Cu}^{2+}$ species contributed to the $\mathrm{Cu} / \mathrm{PKS}$ catalytic activity. Similar reduction activity can be seen for $\mathrm{Cu}-\mathrm{Ce} / \mathrm{PKS}$ in Figure 3(d).
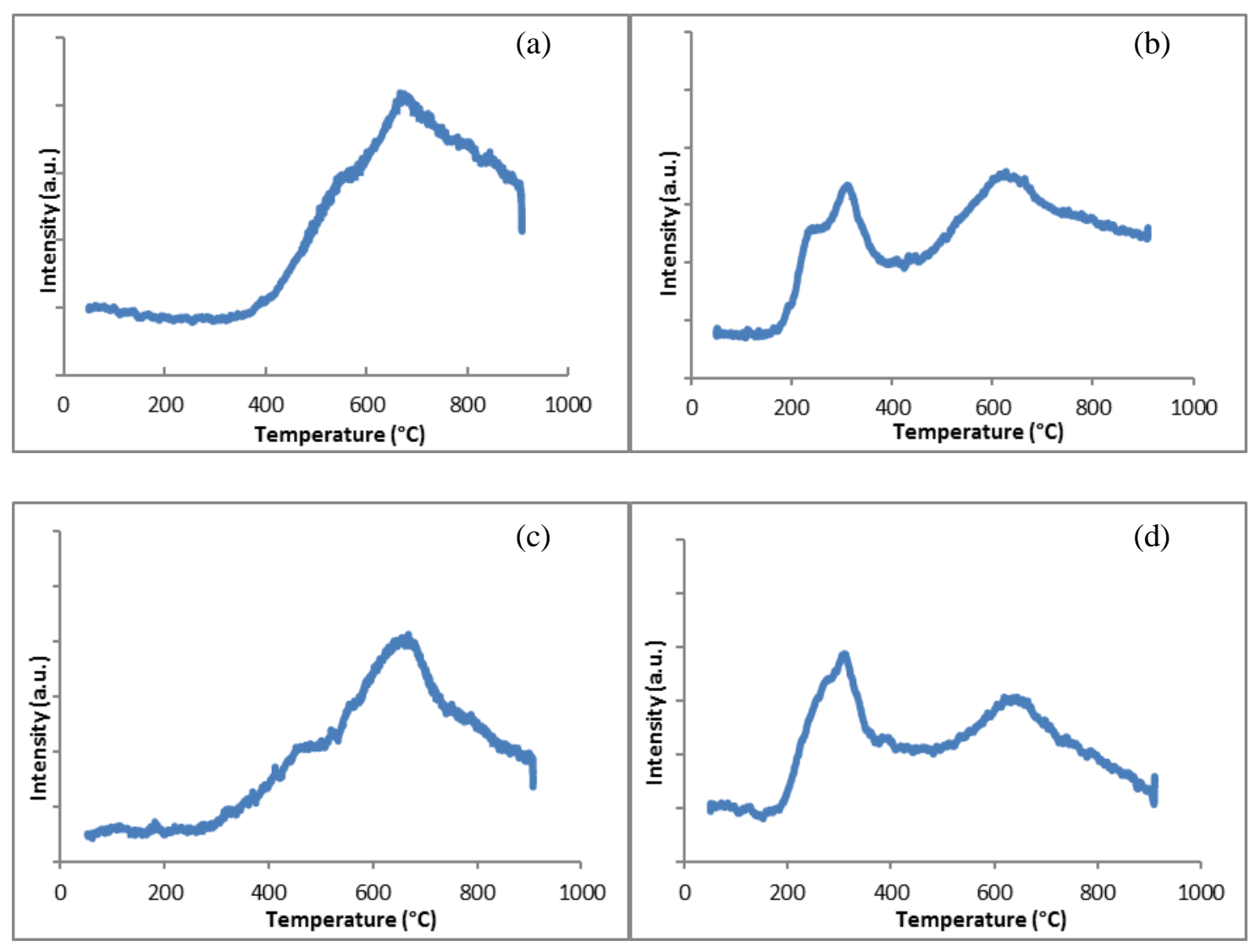

Figure 3. TPR profiles of (a) PKS; (b) Cu/PKS; (c) Ce/PKS; and (d) $\mathrm{Cu}-\mathrm{Ce} / \mathrm{PKS}$.

\subsection{Effects of cerium}

Figure 1 shows that at the temperature equal to the PKS's optimum $\mathrm{NO}_{\mathrm{x}}$ removal temperature, $\mathrm{Ce} / \mathrm{PKS}$ 's capacity for $\mathrm{NO}_{\mathrm{x}}$ removal dropped drastically by $35 \%$. This was due to the lower surface area and pore volume of the catalyst, as discussed in the previous section (see Table 2). In addition, it was suggested that the deactivation of $\mathrm{Ce} / \mathrm{PKS}$ occurred at high temperature due to the sintering of the metal particles that leads to a loss of metal surface area and to the loss of $\mathrm{CeO}_{2}$ surface area. As a result, cerium may have lower oxygen storage capacity (OSC) at this temperature [31].

However, the de- $\mathrm{NO}_{\mathrm{x}}$ performance and temperature window for $\mathrm{Ce} / \mathrm{PKS}$ were higher than PKS at low temperature. This showed that Ce had widened the temperature window for SCR at low temperatures. Other cerium-based bimetallic catalysts were also found to possess a low-temperature window below $180{ }^{\circ} \mathrm{C}$ [16] [32] [33]. However, Lamacz et al. (2013) [34] reported a higher temperature window $\left(215-325^{\circ} \mathrm{C}\right)$ for $\mathrm{CuO} / \mathrm{CeZrO}_{2}$ catalyst in $\mathrm{HC}-\mathrm{SCR}$. 
Figure 3(c) shows that Ce/PKS had lower hydrogen reduction activity as compared to PKS. As pure $\mathrm{CeO}_{2}$ was reported to have reduction peaks at 523 and $658{ }^{\circ} \mathrm{C}$, this implied that $\mathrm{Ce}$ was deposited deep inside the heteroatoms of the carbon that had a wide reduction peak from 400 to 900 ${ }^{\circ} \mathrm{C}$ [35]. Besides, the increased performance in comparison to PKS suggested that Ce had assisted in releasing and storing oxygen, as discussed by $\mathrm{Chu}$ et al. (2015) [36]. This is an important step in an $\mathrm{SCR}$ as chemisorbed oxygen is used to convert $\mathrm{NO}$ to $\mathrm{NO}_{2}$ in the fast SCR mechanism [37].

\section{Conclusion}

A passive nitrogen oxides removal system consisting of carbon-supported transitional metal catalyst without the use of ammonia was studied. A bimetallic copper-cerium catalyst was impregnated onto palm kernel shell activated carbon as catalyst support via a deposition-precipitation method. The catalyst was tested in a passive catalytic removal of an in-situ $\mathrm{NO}_{\mathrm{x}}$ generation by a diesel engine. The highest total $\mathrm{NO}_{\mathrm{x}}$ removal was $66 \%$ at $140{ }^{\circ} \mathrm{C}$ by $\mathrm{Cu}-\mathrm{Ce} / \mathrm{PKS}$. An XRF analysis showed that the $\mathrm{Cu}-\mathrm{Ce}$ synergistic effect improved the metal distribution on the carbon surface. PKS plays an important role in providing the high surface area and, the unsaturated and oxygenated surface functional groups for the adsorption of $\mathrm{NO}_{\mathrm{x}}$ species. As copper is reducible at low temperature, it is reactive and is seen to lower the optimum temperature of the catalyst. Cerium, on the other hand, widening the temperature window for the reaction. In conclusion, this biomass-carbon catalyst has a high potential to be developed into an efficient $\mathrm{NO}_{\mathrm{x}}$ removal catalyst. Therefore, it is pertinent to continue focusing on the development of the bimetallic catalysts deposited on PKS for lowtemperature passive SCR application.

\section{Acknowledgements}

The authors acknowledge Universiti Malaysia Sarawak for the Cross-Disciplinary Research grant F02/CDRG/1843/2019 as well as Catalysis Science and Technology Research Centre (Universiti Putra Malaysia) and Nanotechnology \& Catalysis Research Centre (Universiti Malaya) for the research facilities.

\section{References}

[1] Wang, Z., Zhou, J., Zhu, Y., Wen, Z., Liu, J. and Cen, K. (2007). Simultaneous Removal of $\mathrm{NO}_{\mathrm{x}}, \mathrm{SO}_{2}$ and $\mathrm{Hg}$ in Nitrogen Flow in a Narrow Reactor by Ozone Injection: Experimental Results, Fuel Processing Technology; Vol. 88, 817-823.

[2] Wang, M., Liu, H., Huang, Z-H. and Kang, F. (2014). Activated Carbon Fibers Loaded with $\mathrm{MnO}_{2}$ for Removing NO at Room Temperature, Chemical Engineering Journal, Vol.256, 101-106.

[3] Marnellos, G.E., Efthimiadis, E.A. and Vasalos, I.A. (2004). Mechanistic and Kinetic Analysis of the $\mathrm{NO}_{\mathrm{x}}$ Selective Catalytic Reduction by Hydrocarbons in Excess $\mathrm{O}_{2}$ over $\mathrm{In} / \mathrm{Al}_{2} \mathrm{O}_{3}$ in the Presence of $\mathrm{SO}_{2}$ and $\mathrm{H}_{2} \mathrm{O}$, Applied Catalysis B: Environmental; Vol.48, 1-15.

[4] Theinnoi, K., Sitshebo, S., Houel, V., Rajaram, R.R. and Tsolakis, A. (2008). Hydrogen Promotion of LowTemperature Passive Hydrocarbon-Selective Catalytic Reduction (SCR) over a Silver Catalyst, Energy \& Fuel; Vol.22, 4109-4114.

[5] Prasad, R. and Rattan, G. (2010). Preparation Methods and Applications of $\mathrm{CuO}-\mathrm{CeO}_{2}$ Catalysts: A Short Review, Bulletin of Chemical reaction Engineering \& Catalysis, Vol. 5, No. 1, 7-30.

[6] Worch, D., Suprun, W. and Glaser, R. (2011). Supported Transition Metal-Oxide Catalysts for HC-SCR deNO ${ }_{x}$ with Propene, Catalysis Today, Vol.176, 309-313. 
[7] Shanmugapriya, K., You, H-S., Lee, H-C., Park, D.R., Lee, J-S. and Lee, C.W. (2007). A Study of NO+CO Reaction over Various Supported Catalysts in the Presence of $\mathrm{O}_{2}$ and $\mathrm{H}_{2} \mathrm{O}$, Bulletin of the Korean Chemical Society, Vol.28, No.6, 1039-1041.

[8] Chen, X., Gao, S., Wang, H., Liu, Y. and Wu, Z. (2011). Selective Catalytic Reduction of NO over Carbon Nanotubes Supported $\mathrm{CeO}_{2}$, Catalysis Communications; Vol.14, 1-5.

[9] Bansal, R. and Goyal, M. (2005). Activated Carbon Adsorption. Boca Raton, Florida: CRC Press.

[10] Ampelli, C., Perathoner, S. and Centi, G. (2014). Carbon-based Catalysts: Opening New Scenario to Develop Next-Generation Nano-Engineered Catalytic Materials, Chinese Journal of Catalysis; Vol.35, 783-791.

[11] Daud, W.M.A.W., Ali, W.S.W. and Sulaiman, M.Z. (2000). The Effects of Carbonization Temperature on Pore Developement in Palm-Shell-Based Activated Carbon, Carbon, Vol. 38, 1925-1932.

[12] Economic Planning Unit, Prime Minister's Department Malaysia. Statistic of Major Agriculture Product. Retrieved from http://www.epu.gov.my/en/statistic-of-major-agriculture-product; 16 October, 2015.

[13] Malaysian Palm Oil Board. Oil Palm Planted Area As At Dec 2014.3112 2014. [Online]. Retrieved from http://bepi.mpob.gov.my/index.php/statistics/area/132-area-2014/713-oil-palm-planted-area-dec-2014.html; 16 October, 2015.

[14] Nor, N.M., Chung, L.L., Teong, L.K. and Mohamed, A.R. (2013). Synthesis of Activated Carbon from Lignocellulosic Biomass and its Applications in Air Pollution Control - A Review, Journal of Environmental Chemical Engineering; Vol.1, 658-666.

[15] Pang, L., Fan, C., Shao, L., Song, K., Yi, J., Cai, X., Wang, J., Kang, M. and Li, T. (2014). The Ce Doping Cu/ZMS-5 as a New Superior Catalyst to Remove NO from Diesel Engine Exhaust, Chemical Engineering Journal; Vol.253, 394-401.

[16] Dou, B., Lv, G., Wang, C., Hao, Q. and Hui, K. (2015). Cerium Doped Copper/ZSM-5 Catalysts Used for the Selective Catalytic Reduction of Nitrogen Oxide with Ammonia, Chemical Engineering Journal; Vol.270, 549-556.

[17] Muniz, J., Marban, G. and Fuertes, A. (2000). Low Temperature Selective Catalytic Reduction of NO over Modified Activated Carbon Fibres, Applied Catalysis B: Environmental; Vol.27, 27-36.

[18] Li, P., Lu, P., Zhai, Y., Li, C., Chen, T., Qing, R. and Zhang, W. (2015). Low Temperature SCR of NO with Catalysts Prepared by Modified ACF Loading Mn and Ce: Effects of Modification Method, Environmental Technology, Vol.36, No.18, 2390-2400.

[19] Chen, J., Cao, F., Qu, R., Gao, X. and Cen, K. (2015). Bimetallic Cerium-Copper Nanoparticles Embedded in Ordered Mesoporous Carbons as Effective Catalysts for the Selective Catalytic Reduction of NO with $\mathrm{NH}_{3}$, Journal of Colloid and Interface Science, Vol.456, 66-75.

[20] Fan, X., Qiu, F., Yang, H., Tian, W., Hou, T. and Zhang, X. (2011). Selective Catalytic Reduction of $\mathrm{NO}_{\mathrm{x}}$ with Ammonia over Mn-Ce- $\mathrm{O}_{\mathrm{x}} / \mathrm{TiO}_{2}$-Carbon Nanotube Composites, Catalysis Communications, Vol.12, 1298-1301.

[21] Lu, P., Li, C., Zeng, G., He, L., Peng, D., Cui, H., Li, S. and Zhai, Y. (2010). Low Temperature Selective Catalytic Reduction of NO by Activated Carbon Fiber Loading Lanthanum Oxide and Ceria, Applied Catalysis B: Environmental; Vol.96, 157-161.

[22] Ma, Z., Yang, H., Li, Q., Zheng, J. and Zhang, X. (2012). Catalytic Reduction of NO by $\mathrm{NH}_{3}$ over Fe-Cu$\mathrm{O}_{\mathrm{x}} / \mathrm{CNTs}-\mathrm{TiO}_{2}$ Composites at low Temperature, Applied Catalysis A: General; Vol. 427-428, 43-48.

[23] Shu-li, B., Jiang-hong, Z., Li, W. and Zhen-ping, Z. (2009). Study of Low-Temperature Selective Catalytic Reduction of NO By Ammonia over Carbon-Nanotube-Supported Vanadium, Journal of Fuel Chemistry and Technology; Vol.37, No.5, 583-587.

[24] Pasel, J., Kabner, P., Montanari, B., Gazzano, M., Vaccari, A., Makowski, W., Lojewski, T., Dziembaj, R. and Papp, H. (1998). Transition Metal Oxides Supported on Active Carbons as Low Temperature Catalysts for the Selective Catalytic Reduction (SCR) of $\mathrm{NO}$ with $\mathrm{NH}_{3}$, Applied Catalysis B: Environmental, Vol.18, 199-213. 
[25] Huang, B., Huang, R., Jin, D. and Ye, D. (2007). Low Temperature SCR of NO with $\mathrm{NH}_{3}$ over Carbon Nanotubes Supported Vanadium Oxides, Catalysis Today, Vol.126, 279-283.

[26] Iwamoto, M., Yahiro, H., Shundo, S., Yu-u, Y. and Mizuno, N. (1991). Influence of Sulfur Dioxide on Catalytic Removal of Nitric Oxide over Copper Ion-Exchanged ZSM-5 Zeolite, Applied Catalysis, Vol. 69, L15-L19.

[27] Zhu, L., Zhang, L., Qu, H. and Zhong, Q. (2015). A Study on Chemisorbed Oxygen and Reaction Process of $\mathrm{Fe}-\mathrm{CuO}_{\mathrm{x}} / \mathrm{ZSM}-5$ via Ultrasonic Impregnation Method for Low-Temperature $\mathrm{NH}_{3}-\mathrm{SCR}$, Journal of Molecular Catalysis A: Chemical; Vol.409, 207-215.

[28] Mrad, R., Aissat, A., Cousin, R., Courcot, D. and Siffert, S. (2015). Catalysts for $\mathrm{NO}_{\mathrm{x}}$ Selective Catalytic Reduction by Hydrocarbons (HC-SCR), Applied Catalysis A: General; Vol.504, 542-548.

[29] Rodriguez, J.A., Kim, J.Y., Hanson, J.C., Perez, M. and Frenkel, A.I. (2003). Reduction of CuO in $\mathrm{H}_{2}$ : in situ Time-Resolved XRD Studies, Catalysis Letters; Vol.85, No.3-4, 247-254.

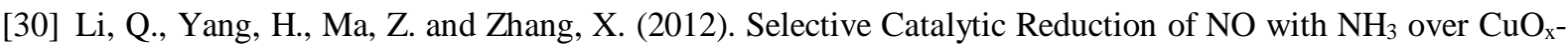
Carbonaceous Materials, Catalysis Communications; Vol.17, 8-12.

[31] Cao, F., Xiang, J., Su, S., Wang, P., Sun, L., Hu, S. and Lei, S. (2014). The Activity and Characterization of $\mathrm{MnO}_{\mathrm{x}}-\mathrm{CeO}_{2}-\mathrm{ZrO}_{2} / \mathrm{y}-\mathrm{Al}_{2} \mathrm{O}_{3}$ Catalysts for Low Temperature Selective Catalytic Reduction of $\mathrm{NO}$ with $\mathrm{NH}_{3}$, Chemical Engineering JournaL, Vol.243, 347-354.

[32] Liu, K., Yu, Q., Qin, Q. and Wang, C. (2017). Selective Catalytic Reduction of Nitric Oxide with Carbon Monoxide over Alumina-Pellet-Supported Catalysts in the Presence of Excess Oxygen, Environmental Technology, Vol.39, No.15, 1878-1885.

[33] Dai, X., Jiang, W., Wang, W., Weng, X., Shang, Y., Xue, Y. and Wu, Z. (2018). Supercritical Water Syntheses of Transition Metal-Doped $\mathrm{CeO}_{2}$ Nano-Catalysts for Selective Catalytic Reduction of NO by CO: An in situ Diffuse Reflectance Fourier Transform Infrared Spectroscopy Study, Chinese Journal of Catalysis, Vol39, 728-735.

[34] Lamacz, A., Krzton, A. and Djega-Mariadassou, G. (2013). Study on the Selective Catalytic Reduction of $\mathrm{NO}$ with Toluene over $\mathrm{CuO} / \mathrm{CeZrO}_{2}$. A Conformation for the Three-Function Model of HC-SCR Using the Temperature Programmed Methods and in situ DRIFT, Applied Catalysis B: Environmental, Vol.142-143, 268-277.

[35] Zhu, P., Lu, M. and Zhou, R. (2012). Effect of Interaction between $\mathrm{CuO}$ and $\mathrm{CeO}_{2}$ on the Performance of $\mathrm{CuO}-\mathrm{CeO}_{2}$ Catalysts for Selective Oxidation of $\mathrm{CO}$ in $\mathrm{H}_{2}$-Rich Streams, Indian Journal of Chemistry; Vol.51A, 1529-1537.

[36] Yinghao, C., Tengteng, Z., Jiaxiu, G., Chao, L., Huaqiang, Y., Xiaofan, Z. and Yongjun, L (2015). Low Temperature Selective Catalytic Reduction of NO by $\mathrm{C}_{3} \mathrm{H}_{6}$ over $\mathrm{CeO}_{\mathrm{x}}$ Loaded on $\mathrm{AC}$ Treated by $\mathrm{HNO}_{3}$, Journal of Rare Earth, Vol.33, No.4, 371-381.

[37] Chen, L., Weng, D., Si, Z. and Wu, X. (2012). Synergistic Effect between Ceria and Tungsten Oxide on $\mathrm{WO}_{3}-\mathrm{CeO}_{2}-\mathrm{TiO}_{2}$ Catalysts for $\mathrm{NH}_{3}-\mathrm{SCR}$ Reaction, Progress in Natural Science: Materials International, Vol.22, No.4, 265-272. 